University of Washington Tacoma

UW Tacoma Digital Commons

SIAS Faculty Publications

School of Interdisciplinary Arts and Sciences

$12-1-2017$

\title{
Impacts of Inquiry Pedagogy on Undergraduate Students Conceptions of the Function of Proof
}

Emily Cilli-Turner

University of Washington Tacoma, emilyct@uw.edu

Follow this and additional works at: https://digitalcommons.tacoma.uw.edu/ias_pub

\section{Recommended Citation}

Cilli-Turner, Emily, "Impacts of Inquiry Pedagogy on Undergraduate Students Conceptions of the Function of Proof" (2017). SIAS Faculty Publications. 795.

https://digitalcommons.tacoma.uw.edu/ias_pub/795

This Article is brought to you for free and open access by the School of Interdisciplinary Arts and Sciences at UW Tacoma Digital Commons. It has been accepted for inclusion in SIAS Faculty Publications by an authorized administrator of UW Tacoma Digital Commons. 


\title{
Impacts of Inquiry Pedagogy on Undergraduate Students' Conceptions of the Function of Proof
}

\begin{abstract}
:
Mathematicians and mathematics educators agree that proof is an important tool in mathematics, yet too often undergraduate students see proof as a superficial part of the discipline. While proof is often used by mathematicians to justify that a theorem is true, many times proof is used for another purpose entirely such as to explain why a particular statement is true or to show mathematics students a particular proof technique. This paper reports on a study that used a form of inquiry-based learning (IBL) in an introduction to proof course and measured the beliefs of students in this course about the different functions of proof in mathematics as compared to students in a non-IBL course. It was found that undergraduate students in an introduction to proof course had a more robust understanding of the functions of proof than previous studies would suggest. Additionally, students in the course taught using inquiry pedagogy were more likely to appreciate the communication, intellectual challenge, and providing autonomy functions of proof. It is hypothesized that these results are a response to the pedagogy of the course and the types of student activity that were emphasized.
\end{abstract}

Keywords: inquiry-based learning, function of proof, introduction to proof course

\section{Introduction}

Proof is the main component of pure mathematical practice (Rav, 1999) and is the heart of what most mathematicians do; however, the role of proof can vary depending on the context of its presentation or creation. For instance, one can use proof to validate a conjecture that was made during mathematical research, but when that proof is published or presented it is being used more to communicate an idea. Mathematics students may use proof not as much to validate a conjecture, but to explain why a particular statement is true or to shed light on the structure of mathematics, while mathematics instructors can use proof to teach techniques to students and to explain why certain statements are true. While we may agree as mathematicians and educators that proof fills the roles outlined above, our students may not appreciate how crucial proof is to the discipline or its many different facets. Even more concerning, students may perceive proof in mathematics as needed merely for justification (Weber, 2002) or as something required only by a teacher and unimportant to the nature of the discipline (Alibert and Thomas, 1991).

It is hypothesized that informing students about these additional functions of proof when teaching can be advantageous (Hanna, 1990; Knuth, 2002a) and that "the more fundamental function of explanation should be exploited to present proof as a meaningful activity to pupils" (de Villiers, 1990, p. 23). However, in most transition to proof courses, which would be the natural class in which to discuss such things, explicit instruction on the functions of proof is not a normal part of the curriculum and so may not be taught. Thus, it is crucial to determine which functions of proof students in a transition to proof course, where they will likely be exposed to proof-writing for the first time in their studies, may already understand and appreciate, as well as to explore pedagogical ways to increase appreciation of the many roles of proof without spending class time to teach such things. Therefore, the present study aimed to identify students' 
perceptions of the function of proof before and after a transition to proof course as well as to determine if an inquiry pedagogy can enhance students' understandings of the functions of proof beyond verification. This paper reports on this study and attempts to answer the following research questions:

1) What understanding do students have of the many functions of proof in mathematics?

2) Does exposure to an inquiry pedagogy impact these understandings?

\section{Functions of Proof}

While I will not go into answering the philosophical question of "What constitutes a proof?" in this paper, many definitions of proof put forth by mathematicians and mathematics educators alike focus on the verification power of proof. For instance, the mathematician Krantz (2007) defines proof as "a rhetorical device for convincing another mathematician that a given statement (the theorem) is true" (pg. 3). This reflects a common adage, taken from Mason et al. (1982), that one should develop an argument by first convincing yourself, then by convincing a friend and finally by convincing an enemy. These definitions of proof make clear that the primary, and per- haps only, function of proof is that of verifying that a given statement is true and then convincing others of your result.

A careful analysis of the functions of proof present in teaching and research paints a different picture. A literature review exposes the multitude of roles that proof can play in mathematics beyond merely verification of a statement. In fact, de Villiers (2012) cautions that defining proof as having purpose only for verification of statements can obscure other functions of proof that are perhaps more fruitful in a pedagogical context. I present an outline of eight other functions of proof from the mathematics education literature. These additional functions of proof will be used as a framework for our analysis undertaken to answer the two research questions.

Hanna (1990) and de Villiers (1990) demonstrate that some proofs can be explanatory and provide insight as to why a certain statement is true rather than just show that it is true. Hanna (1990) uses the example of two proofs of the statement "The sum of the first $n$ positive

integers, $S(n)$, is equal to $\frac{n(n+1)}{2}$,. A proof of this statement by mathematical induction may give insight into why this formula works for all natural numbers $n$, but gives no clarification about how the formula $\frac{n(n+1)}{2}$ was obtained. On the other hand, Hanna (1990) gives the proof in Figure 1 as one that proves the statement and also gives an explanation of how this formula was obtained, which she terms a proof that explains.

Beyond proof as explanation, de Villiers (1990) presents three additional functions of proof in mathematics. The first is the use of proof as a means of discovery since proof can sometimes lead to new results in a field. For example, proofs may be analyzed resulting in a conjecture of a more general case. Indeed, Lakatos (1976) shows that the method of proof analysis, where, upon emergence of a counterexample, proofs and definitions are reanalyzed, is exactly the way that mathematics progressed throughout history and was a catalyst for the emergence of new fields. A second function of proof identified by deVilliers is that of an intellectual challenge to the prover. The completion of a proof can be very satisfying for mathematicians and analogous to solving a puzzle. Third, proof can expose logical relationships between statements and can serve as a tool for axiomatizing results in a mathematical system. If 
another statement is used in a proof, we can consider that an axiom or lemma needed for that result and, comparatively, if a further statement is the consequence of that proof we consider it a corollary. This provides a way to determine a hierarchy of statements in mathematics.

One reason that proofs are of the utmost importance in mathematics is that they, instead of axioms and theorems, are the main vehicles in which mathematical knowledge is contained and transferred (Rav, 1999; Hanna and Barbeau, 2011). Thus, proof serves an important communication role. Mathematicians talk to each other in the language of proof expressed in publications and presentations. Furthermore, Weber (2002) claims that proof can serve as the justification for a definition in mathematics. For instance, Weber (2002) cites the use of Peano arithmetic axioms to prove simple statements such as $2+2=4$. It is unlikely that this would be proven for verification purposes since it is a simple statement that one is already convinced by, but a proof would instead aim to determine if the axioms of Peano arithmetic are reasonable ones. Weber (2002) also posits that proof can illustrate techniques in advanced mathematics. The author gives the example of instructors asking students to prove that $f(x)=x^{2}$ is a continuous function. Most students already have an intuitive understanding of why this statement should be true, however the construction of a proof this statement can demonstrate certain techniques for proving statements about continuous functions.

$$
\begin{aligned}
& \text { A proof that explains. } \\
& \text { Let } \quad S(n)=1+2+\cdots+n \\
& \text { Then, } S(n)=n+(n-1)+\cdots+1 \\
& \text { So, } 2 S(n)=(n+1)+(n+1)+\cdots+(n+1)=n(n+1) \\
& \text { Thus, } S(n)=\frac{n(n+1)}{2}
\end{aligned}
$$

Figure 1: A proof of the statement "The sum of the first $\mathrm{n}$ positive integers, $\mathrm{S}(\mathrm{n})$, is equal $\frac{n(n+1)}{2}$, that explains (Hanna, 1990, pg. 10).

Finally, Yackel and Cobb (1996) comment that another role of proof can be to provide autonomy to students by allowing them to verify statements for themselves and, in some cases, to create their own mathematical knowledge. This can be important as it gives students access to the main component of mathematical practice and can allow them to identify as mathematicians.

While it is important to enumerate all the functions of proof from the literature, I strongly agree with the statement by Weber (2002) that "some proofs can fall into multiple categories; others might fall into none." He gives the example of Euclid's proof of the infinitude of primes. The proof of this statement, as traditionally presented to introduction to proof students, can serve to illustrate the technique of proof by contradiction, convince the student that this statement is indeed true and simultaneously explain why the statement is true by creating a new integer from the product of a finite list of primes and showing that this number necessitates a new prime that is not in the list. De Villiers (1990) also comments that even though functions of proof "can be distinguished from one another, they are often intricately linked in specific cases" (pg. 23).

It is student appreciation of these functions of proof from the literature (i.e. verification, explanation, discovery, intellectual challenge, axiomatizing, communication, justifying definitions, illustrating techniques and providing autonomy) that this study explored.

\section{Student Understandings of Proof Function}


At the K-12 level, results indicate that while many teachers perceive a robust function of proof, this perception is rarely passed along to students. Healy and Hoyles (2000) found in a study of 14-15 year old students in the United Kingdom that $50 \%(\mathrm{~N}=2459)$ of the students referred to proof as having a verification function, $35 \%$ identified an explanation function and only $1 \%$ perceived a discovery or axiomatizing function of proof. Additionally, they found that $28 \%$ of the students surveyed "had little or no idea of the meaning of proof and what it was for" (pg. 418). A study by Knuth (2002a) interviewed in-service secondary school teachers about their conceptions of proof in mathematics. Results indicate that verification was the primary function of proof identified, with all of the sixteen teacher participants referring to proof for establishing truth of a statement. Twelve of the teachers spoke about the communication function of proof and eight referred to the role of proof in axiomatizing results, while only three of the teachers provided explanation as a function of proof. Results of this study also indicated that inservice K-12 teachers understand that proof plays multiple roles in mathematics, but may not be teaching these functions to their students.

At the undergraduate level, evidence exists that mathematicians are naturally aware of the various functions of proof and report conveying these functions of proof to their students (Weber, 2012; Nardi, 2008). There is some debate, however, about the recognition of proof function amongst undergraduate students and few studies around student recognition of proof function have been done at the undergraduate level. Almeida (1995) found in a study of secondyear undergraduates that students did appreciate proof as explanatory as well as for verification, but that they did not identify proof as a means of communicating mathematics. Similarly, a study with advanced undergraduate mathematics students by Coe and Ruthven (1994) found that "the most commonly expressed function of proof was to ensure the certainty of what is proved" (pg. 50). However, Coe did find that several students recognized the role of proof in organizing mathematical statements into a hierarchy. Furthermore, in this study several students related a different function of proof, that of better understanding the concepts in mathematics, which is consistent with Knuth (2002b). The studies presented above agree with the hypotheses of Moore (1994) and Weber (2002) that undergraduate students appreciate the role of proof to explain and convince, but most do not understand the other functions of proof outlined in the literature. Weber (2002) argues that this may apply to mathematicians as well when he writes "I suspect that most students and perhaps some mathematicians believe that convincing and explaining are the only purposes of proof' (pg. 15). It is important to note that the studies of Almeida (1995) and Coe and Ruthven (1994) employed small sample sizes of students, with these studies interviewing 10 and 7 students, respectively.

However, more recent research has exposed some limitations of prior studies and gave an indication that students may understand more about proof function than originally thought. Stylianou et al. (2015) conducted a study that gave a survey to undergraduate students that included evaluation of the validity of several proof attempts as well as questions regarding their perceptions of the meaning and function of proof. Using the results of the items on validating proofs, students were classified as low or high-achieving. Results showed that $86 \%$ of the highachieving students agreed with the statement "Proofs serve the purpose of not only validating mathematical conjectures, but also of communicating and explaining new ideas", and $58 \%$ of the low-achieving students agreed with the same statement. These results show a much higher percentage of students see proof as necessary for more than verification purposes.

A robust understanding of the myriad functions of proof is agreed upon by the authors 
cited in this section as important in the learning of mathematics and mathematical proof. De Villiers (1990) argues that informing students about these additional functions of proof when teaching can be advantageous and Hanna (1990) believes instructors can help students understand certain concepts by substituting proofs that are explanatory for proofs that are not, whenever possible. Given the teaching implications, it is desirable to develop methods of teaching that give students a chance to experience these other functions of proof. However, at present there are no studies about pedagogical practices that can promote the different roles of proof. Additionally, there are few studies studying undergraduate student perceptions of functions of proof and essentially no research studying any of the functions of proof beyond verification, explanation, communication, axiomatizing and discovery. Since there seems to be consensus in the literature about importance of understanding proof functions, this study aims to "capitalize on the robust foundation offered by prior theoretical and empirical work in order to refine existing or design new interventions to alleviate some of the many problems of classroom practice in the area of proof" as stated by Stylianides et al. (2017). Thus, a primary goal of this study is to explore these other roles of proof are determine which are understood by undergraduate students in an introduction to proof course as well as to determine if students' beliefs about proof evolve due to participation in an inquiry mathematics course.

\section{Methodology}

The inquiry pedagogy employed in this study is termed collaborative revision (Author, 2013). Much like a peer review process that students engage in during a writing course, students were expected to complete the proof of a statement before coming to class and classroom time was spent "workshopping" the proof. This shares characteristics with inquiry-based learning (IBL) or Moore method courses in that students completed proofs outside of class and presented those proofs in class. However, students in this environment did not present their proof to the whole class, but instead a small group of 2-3 other students. The other students were encouraged to make comments and point out inconsistencies in order to ensure that the proof is valid and that it is written clearly and coherently. The student would then revise the proof based on feedback from the group discussion and turn it in the following week.

\subsection{Participants \& Groups}

This study was conducted at a large midwestern university with students who were enrolled in an introduction to proof course. All students were enrolled in a section of an introduction to proof course. This course met three times per week for 50 minutes and covered topics of proof method, including direct proof, contradiction and induction, set theory and counting proofs, functions, and some additional topics chosen by the instructor. This course was taught using lecture as the primary mode of content delivery. Students in the treatment group of this study were also enrolled in a one-credit supplementary course, which was taught using the inquiry pedagogy. The supplementary course, which met once per week for 2 hours and was offered through the Emerging Scholars program. This course did not cover any new content, but each week students would engage in the collaborative revision process outlined in the previous section. The comparison group consisted of students that were enrolled in the introduction to proof course, but not the supplementary course. There were a total of 27 undergraduate student participants, with 15 students in the treatment group and 12 in the comparison group.

It is important to note that this was a quasi-experiment, with the comparison course and 
treatment course not formed by random assignation, but self-selection by enrollment. However, precautions have been taken to ensure that the comparison group would still give valid data for the study. Following the guidelines outlined in Shadish et al. (2002) for strengthening a quasiexperimental study, this study uses an internal comparison group, taken from the same class as the students in the treatment group. Additionally, a pre-test was used to "examine selection biases and attrition as sources of observed effects" (Shadish et al., 2002, p. 158). The overall GPA (3.32 in the treatment group and 3.36 in the comparison group) and math GPA (3.33 in the treatment group and 3.22 in the comparison group) of students in both groups was collected and no significant differences in means were found between the groups. Additionally, both groups had similar numbers of female and male students ( 6 females in the treatment group and 7 in the comparison group) and students who were math majors ( 5 in the treatment group and 5 in the comparison group).

\subsection{Context}

\subsubsection{Treatment Course}

The treatment course was designed to maximize the amount of time spent working in groups having students explain and critique proofs in order to enhance students proof validation and construction skills. This course used the collaborative revision process described above, where a student would present a proof they have constructed outside of class to a small group and the group would then provide reactions, observations, and criticisms of the proof. The student presenter would then revise the proof according to the group discussion and present it again, repeating the process until the group reaches a consensus about the validity of the proof.

The following is a description of the day to day activities that took place in the teaching experiment classroom from field notes taken during the sixteen-week semester. For the first two weeks of the semester, class time was spent not on the collaborative revision process, but on familiarizing the students with the collaborative norms of the classroom. In the comparison classrooms as well as previous courses these students had taken, they were used to an environment where they may ask questions occasionally, but were otherwise not encouraged to talk. Thus, it took training for the students to properly engage in the collaborative revision process. These two weeks were spent on the study of mathematical logic and tasks were given to students concerning logical operators, negations of logical statements, truth tables, and logical equivalence, quantifiers and negations of quantifiers. Part of the first class included minimal instruction on the basic structure of direct proofs to make sure students were all at the same level. During these two weeks, students were often asked to work in small groups and discuss prompts or work on problems. The rationale for this was that it takes time to get students used to the adjusted classroom norms that are required when using collaborative revision, such as the role of the teacher as a facilitator and addressing questions directly to each other when working in groups.

Starting in the third week of the semester, the collaborative revision process was explained to students and at the end of class during this week, the students were given their first statement to prove at home. The statements to prove were simple number theory statements regarding divisibility or properties of even and odd numbers. During the fourth week, the first round of collaborative revision took place. Students were put into groups of 3-4 and asked to go through each person's proof, one at a time. The student whose turn it was would write their proof onto a packet of paper handed out by the instructor, meanwhile explaining each step to the other students. The other students were encouraged to ask questions to the presenter and make 
comments on parts they like, parts they do not understand or parts they had logical concerns about. At the end of class, each student handed in their paper to the instructor for inclusion into a proof portfolio.

This structure continued for each of the remaining weeks of the semester. Students would be put into groups with revolving members and either re-present a revision of a proof from a prior week or present a new proof. Each week a new statement to be proven was handed out to each student, which they were to bring in a proof of for the following week. Each set of statements to be proven are focused around a single mathematical topic (see Appendix A for a sample proof set on modular arithmetic). This was done on purpose so that students would presumably have had some experience with the topic while attempting a proof of the statement given to them and, thus, be better able to evaluate their classmates' proofs. All drafts of each proof were collected and put into a proof portfolio to document the revision process.

During the treatment course, the instructor had several roles. The first was to do the preparation work of gathering appropriate proofs to give to the students and to assign groups. As the instructor, I identified many proofs that would be challenging yet solvable and did not appear in the students' regular text, to avoid giving students a mathematical statement that they may have already proven. Formation of groups also becomes an important task for the instructor in a collaborative revision classroom. Groups of students were assigned for each new round of student presentations and the same groups were kept during each iteration of proof revisions. The instructor also needed to circulate to regulate and facilitate discussions. As instructor, I often needed to aid groups that were stuck on a particular task. This sometimes took the form of the presenting a certain example or counterexample to the students to help them with their arguments or suggesting a direction in which to proceed. Finally, the most important role of the instructor was to create an environment of collaboration in the classroom. This included asking students to direct their comments and questions towards other students instead of the instructor and stepping away from the front of the classroom to denote a facilitator role. This was often also the most difficult role, as students were unaccustomed to this type of classroom setup and were used to the instructor being in front of the class and transmitting the information. Students also tended to be uncritical of their colleagues' proofs, which could be due to inexperience at validating proofs or a due to wanting to spare a classmates' feelings. Thus, I spent a lot of time at the beginning of the course asking my own questions about the students' proofs and asking some of the other students if they understood certain parts and if they could explain that argument in their own words. This often resulted in many more questions being asked about the proof and during the later weeks of the semester I did not need to do this as much as the students had adopted a more questioning attitude.

\subsubsection{Comparison Course}

What follows is a description of the learning environment provided to students in the comparison course. The descriptions are taken from field notes taken during observations of course sessions. Course websites and syllabi were also examined to determine the topics being covered in each section and the course grading structure. The comparison group included students enrolled in two sections of the introduction to proof course at the university. I visited each of these sections twice during the semester to observe the learning environment. During my first observation, each of the section instructors lectured on the topic chosen for that day and presented definitions and axioms and then gave proofs of several theorems. The environment was such that students were encouraged to ask questions if they did not understand a concept or a 
part of a proof. In my observation, several students did ask such questions and the instructor expertly answered their concerns. There was no group work or whole-class discussion that took place in either section during my first observation. The instructor lectured for roughly $90 \%$ of the class time with the other $10 \%$ used up by student questions and housekeeping things (i.e. passing back homework, talking about test dates, etc.).

During the second observation, one of the sections remained unchanged. Again, the professor went through the material to be covered and presented more definitions and proofs. It was still about $90 \%$ lecture and $10 \%$ questions and miscellaneous things to be discussed. The other section was run slightly differently. Since it was the last week of the semester, the other section was preparing for the final and having a review session. Students were asking about statements to be proved off of a review sheet provided by the professor and the professor was going through the proof. This resulted in the instructor at the board filling about $80 \%$ of the time and the students asking questions from the review sheet and about the proofs the instructor was writing taking up about $20 \%$ of the time.

\subsection{Data Collection \& Analysis}

To gain an understanding of students' perceptions of proof function, a survey was administered. As it can be difficult to determine appreciation of a function of proof, it was decided that the most straightforward way to obtain this information would be to explicitly ask for it. The lack of a verified instrument about undergraduate students' understandings of these particular functions of proof in the literature necessitated the creation of the simple survey shown in Table 1. We acknowledge the limitations of this survey as designed, yet the results from this survey are worthy reporting. Students were given this survey during the first and final weeks of the semester that asked them to rate their agreement on a 5-point Likert scale with several statements about the function of proof in mathematics. The eight statements that students were to rate from 1, indicating strong disagreement, to 5, indicating strong agreement, are shown in Table 1. The proof function regarding illustrating a technique is not addressed since it was determined that this would be difficult for students to assess as it is mostly a proof function that is demonstrated by an instructor. For ease of reporting, the topic of each statement is identified and we will hence refer to that statement by its associated proof function. Note that statement 2 was written negatively while all other statements were written positively. Thus, a Likert rating closer to 1 indicates a belief that proof is needed not only for verification purposes, but may serve another function. Due to the small sample size and the ordinal nature of this data, analysis was done using a Mann-Whitney U Test.

\section{Results}

A major finding of this study is that, upon entering an introduction to proof course, students tend to have a more robust understanding of functions of proof than previously thought. Table 2 shows the mean and standard deviation of Likert ratings on each statement on the presurvey. Students in both the treatment and comparison groups in this study were found to have strong agreement with statements addressing functions of proof distinct from verification. The table shows that students agree strongly with proof as a tool for explanation, discovery, communication and axiomatization with all these means close to 5. Students in both the treatment and comparison groups in this study were found to have strong agreement with statements addressing functions of proof distinct from verification. None of the differences in 
means between the treatment and comparison groups were significant indicating that students in both groups entered the introduction to proof course with similar beliefs. These results are not consistent with the outcomes of Almeida (1995), who found that undergraduate students did not recognize many functions of proof beyond explanation and verification, or Coe and Ruthven (1994), who found that some undergraduate students did recognize the function of proof in axiomatizing statements, but many cited proof as merely for explanation or convincing purposes. This may partly be due to the fact that this study expands on these previous studies, each of which examined only up to five separate proof functions, by using eight proof functions identified in the literature as a framework for data analysis. The results from the pre-survey track more closely with the results of Stylianou et al. (2015) and indicate that students in an introduction to proof course seem to exhibit awareness of many different functions of proof.

\begin{tabular}{ll} 
Statement & Topic \\
\hline \hline 1. I believe that proofs are very important in the field & Importance \\
of mathematics. & \\
2. I believe that proofs are only done to verify whether & Verification \\
a given statement is true or false. & \\
3. A proof can explain why a given statement is true. & Explanation \\
4. I enjoy writing proofs because they are intellectu- & Challenge \\
ally challenging. & \\
5. I believe that proofs are an important communica- & Communication \\
tion tool in mathematics. & \\
6. I believe that proving can be used to discover new & Discovery \\
mathematics. & \\
7. Proofs are important in organizing mathematical & Axiomatizing \\
knowledge. & \\
8. I want to learn proof construction so I can under- & Autonomy \\
stand the language of mathematics and create my own & \\
proofs. &
\end{tabular}

Table 1: The statements on the survey and the proof function associated with each statement.

Students were not given any explicit instruction about the functions of proof in mathematics in either the treatment or comparison courses. Thus, any change in appreciation of these functions must be due to some other aspect of the classroom or content. Our second research question asked after what that specific aspect is. The results in Table 3 provide evidence to believe that the characteristic that makes the difference in appreciation of proof function is the environment encountered when learning to prove. On the post-survey, students in the treatment group rated each statement, on average, higher ${ }^{1}$ than students in the comparison group. Additionally, the means were significantly different regarding three of the proof functions: intellectual challenge, communication, and autonomy. These categories of proof function line up

${ }^{1}$ The statement regarding the verification function of proof was written negatively, so a rating closer to 1 indicates that the student believes that proof has more functions that just that of verification. 


\begin{tabular}{ccccc} 
Statement Topic & & $N$ & $\mathrm{Mean}^{\mathrm{a}}$ & $\mathrm{Std}$. Dev. \\
\hline \hline Importance & Treatment & 15 & 4.73 & 0.59 \\
& Comparison & 12 & 4.67 & 0.49 \\
\cline { 2 - 5 } Verification & Treatment & 15 & 3.07 & 1.44 \\
& Comparison & 11 & 2.64 & 0.92 \\
\cline { 2 - 5 } Explanation & Treatment & 15 & 4.40 & 1.12 \\
& Comparison & 12 & 4.67 & 0.49 \\
\cline { 2 - 5 } Challenge & Treatment & 15 & 3.87 & 0.92 \\
& Comparison & 12 & 3.75 & 0.97 \\
\cline { 2 - 5 } Communication & Treatment & 15 & 4.40 & 0.91 \\
& Comparison & 12 & 4.58 & 0.90 \\
\cline { 2 - 5 } Discovery & Treatment & 15 & 4.53 & 1.13 \\
& Comparison & 12 & 4.42 & 0.79 \\
\cline { 2 - 5 } Automatizing & Treatment & 15 & 4.67 & 0.62 \\
& Comparison & 12 & 4.58 & 0.67 \\
\cline { 2 - 5 } & Treatment & 15 & 4.40 & 0.91 \\
& Comparison & 12 & 4.00 & 1.04 \\
\hline
\end{tabular}

${ }^{a}$ None of the mean differences are significant (all $p$-values greater than 0.17 ) at the $\alpha=0.05$ level.

Table 2: Means and standard deviations of Likert ratings on each statement for all students on the pre-assessment, separated by group

with the differences between an IBL course and a traditional course. Since students are responsible for much of the content delivery, they are practiced at elucidating their reasoning and discussing with fellow students (Cook et al., 2016). Indeed, in the treatment course, students were engaged every class day in presenting their proofs as well as working with their classmates to revise the proof, which focuses the explaining and communicating around the proof at hand. Additionally, the aspect of the course where students are expected to work on proofs outside of class may have contributed to students sense of autonomy when working on proofs.

Beyond the significant differences in means between the treatment and comparison group, the comparison group, on average, gave a lower rating to all of the statements about proof function, except discovery, on the post-assessment than on the pre-assessment. In the case of the communication function of proof, the comparison group rated it significantly lower on the postassessment. This finding is consistent with the hypothesis of Hanna and Barbeau (2011) and de Villiers (1990) that the traditional instruction environment in proof courses obfuscates the communication aspect of proof. Indeed, Hanna and Barbeau (2011) write that "educators have overlooked to a large extent the role of proof as a bearer of mathematical knowledge in the form of methods, tools, strategies and concepts that are new to the student and add to the approaches the student can bring to bear in other mathematical contexts" (pg. 98). Thus, it is perhaps unsurprising that students in this comparison group did not possess a strong appreciation for this proof function and their ratings of it decreased during the semester. 


\begin{tabular}{clcrl} 
Statement Topic & & $N$ & Mean & Std. Dev. \\
\hline \hline Importance & Treatment & 15 & 5.00 & 0.00 \\
& Comparison & 12 & 4.67 & 0.78 \\
\cline { 2 - 5 } Verification & Treatment & 14 & 2.29 & 1.38 \\
& Comparison & 12 & 2.82 & 1.33 \\
\cline { 2 - 5 } Explanation & Treatment & 15 & 5.00 & 0.00 \\
& Comparison & 12 & 4.67 & 0.49 \\
\cline { 2 - 5 } Challenge & Treatment & 15 & $4.33^{*}$ & 0.82 \\
& Comparison & 12 & 3.58 & 1.08 \\
\cline { 2 - 5 } Communication & Treatment & 15 & $4.73^{*}$ & 0.59 \\
& Comparison & 12 & 4.08 & 1.00 \\
\cline { 2 - 5 } Discovery & Treatment & 15 & 4.87 & 0.52 \\
& Comparison & 11 & 4.45 & 1.04 \\
\cline { 2 - 5 } Axiomatizing & Treatment & 15 & 4.53 & 0.74 \\
& Comparison & 12 & 4.50 & 1.00 \\
\cline { 2 - 5 } Autonomy & Treatment & 15 & $4.67^{*}$ & 0.62 \\
& Comparison & 12 & 4.00 & 1.04 \\
\hline
\end{tabular}

${ }^{*}$ The mean difference is significant $(p<0.05)$ at the $\alpha=0.05$ level.

Table 3: Means and standard deviations of each Likert item on the post-assessment.

\section{Limitations}

The sampling technique used in this study was pragmatic and convenient, which could have several limitations. Students self-selected into the treatment group by their enrollment and study size was restrained by the number of students enrolled in this course. Even though any student enrolled in the comparison course could enroll in the treatment course, it is an additional one-credit course that students take so it is possible that only highly motivated students or students that are already amenable to collaborative work were enrolled. This study addressed this concern by the collecting data from each group on gender, major, GPA, and prior mathematics courses taken to ensure a proper comparison.

An additional limitation is the type of data collected from participants on the sur- vey. The survey was not a verified instrument and did not include several questions about each proof function to tease out nuances in understanding of each proof function. Student interviews that ask further questions about these functions of proof would strengthen the results, but due to logistical and temporal reasons these were not conducted. However, as there is a lack of studies that address pedagogies that enhance students' perceptions of proof functions the results are still important to report. There is a need for future research to create a robust proof function instrument to more accurately measure students' understanding of proof function.

\section{Discussion}

Despite no explicit instruction about the many functions of proof in either group, students 
that were exposed to the inquiry pedagogy, on average, had a greater appreciation for the communication, intellectual challenge and providing autonomy functions of proof. This is perhaps not surprising since it is these very characteristics that are present in an inquiry classroom, but may not be present in a lecture-based classroom. Students in the treatment course were presenting their proofs to each other every class day and were communicating to each other in the language of proof. Thus, it seems they came to appreciate this function of proof more than the students who were not communicating with each other during class time. Students in the treatment course were also consistently explaining their proof to other students and defending the logic of statements or working together to revise the argument and were strongly engaged in the explanation power of proof. One consideration is that students who have not completed an introduction to proof course may have limited exposure to proofs and this may hinder understanding of different proof functions. However, the fact that both groups reported similar beliefs on the pre-survey, yet beliefs diverged on the post survey indicate that the treatment group experienced a shift in their understandings of proof function that can be explained by something other than a new understanding of what a proof is.

As educators, the statement with the most encouraging difference in means regarded the challenge function of proof. On the pre-survey, students in both groups rated the intellectual challenge function of proof lower than all of the other categories with the average ratings in the high 3's indicating a neutral stance on the statement "I enjoy writing proofs because they are intellectually challenging". However, on the post- survey, the average rating on this statement dropped in the comparison group from $\mathrm{M}=3.75$ to $\mathrm{M}=3.58$, but greatly increased in the treatment group from $\mathrm{M}=3.87$ to $\mathrm{M}=4.33$. Many research studies have shown that introduction to proof courses can be very challenging for students (e.g. Moore, 1994; Harel, 2007; Weber, 2010), yet we want our students to rise to this challenge and participate in the nature of the profession and the results of this study argue that inquiry can allow students to achieve an understanding of the roles of proof that is closer the one held by mathematicians and mathematics education researchers. Additionally, students in the treatment group felt that learning proof construction was important so that they could experience autonomy in mathematics and not have to rely on an instructor to dictate which mathematical statements are true or false. Again, this is a practice that mathematics educators strive to see in our students (Yackel and Cobb, 1996; Karakok et al., 2015; Weber et al., 2014), yet struggle with how to encourage (Warfield et al., 2005; Schukajlow and Krug, 2014). The practice of inquiry teaching seems to bridge the gap between just teaching our students concepts and material to teaching them how to think like mathematicians and mathematics educators.

\section{References}

Alibert, D. and M. Thomas (1991). Research on mathematical proof. In D. Tall (Ed.), Advanced mathematical thinking, pp. 215-230. The Netherlands: Kluwer.

Almeida, D. (1995). Mathematics undergraduates' perceptions of proof. Teaching mathematics and its applications 14(4), 171-177.

Author (2013).

Coe, R. and K. Ruthven (1994). Proof practices and constructs of advanced mathematics 
students. British educational research journal 20(1), 41-53.

Cook, S., S. Murphy, and T. Fukawa-Connelly (2016). Divergent definitions of inquiry- based learning in undergraduate mathematics. In 18th Annual Conference on Research in Undergraduate Mathematics Education, Volume 18, Pittsburgh, PA, pp. 1-6.

de Villiers, M. (1990). The role and function of proof in mathematics. Pythagoras 24, 17-24.

de Villiers, M. (2012). An illustration of the explanatory and discovery functions of proof. Pythagoras 33(3), 1-8.

Hanna, G. (1990). Some pedagogical aspects of proof. Interchange 21(1), 6-13.

Hanna, G. and E. Barbeau (2011). Proofs as bearers of mathematical knowledge. In G. Hanna, H. Jahnke, and H. Pulte (Eds.), Explanation and proof in mathematics: Philosophical and educational perspectives, pp. 85-100. New York, NY: Springer.

Harel, G. (2007). Students' proof schemes revisited. In P. Boero (Ed.), Theorems in school, pp. 65-78. Rotterdam, The Netherlands: Sense Publishers.

Healy, L. and C. Hoyles (2000). A study of proof conceptions in algebra. Journal for research in mathematics education 31(4), 396-428.

Karakok, G., M. Savic, G. Tang, and H. El Turkey (2015). Mathematicians' views on undergraduate student creativity. In K. Krainer and N. Vondrova (Eds.), Congress of European research in mathematics education - 9 proceedings, Prague., pp. 1003-1009.

Knuth, E. (2002a). School mathematics teachers' conceptions of proof. Journal for research in mathematics education 33(5), 379-405.

Knuth, E. (2002b). Teachers' conceptions of proof in the context of secondary school mathematics. Journal of mathematics teacher education 5, 61-88.

Krantz, S. (2007). The history and concept of mathematical proof. Unpublished. Retrieved from http://www.math.wustl.edu/ sk/eolss.pdf.

Lakatos, I. (1976). Proofs and refutations. Cambridge, UK: Cambridge University Press.

Mason, J., L. Burton, and K. Stacey (1982). Thinking mathematically. London, UK: AddisonWesley.

Moore, R. (1994). Making the transition to formal proof. Educational studies in mathematics 27, 249-266.

Nardi, E. (2008). Amongst mathematicians and conversations on the teaching and learning of mathematics at university level: The case of visualisation. In 11th International Congress of 
Mathematics Education, Monterrey, Mexico, pp. 44-64.

Rav, Y. (1999). Why do we prove theorems? Philosophia mathematica 7(1), 5-41.

Schukajlow, S. and A. Krug (2014). Do multiple solutions matter? prompting multiple solutions, interest, competence, and autonomy. Journal for research in mathematics education 45(4), 497-533.

Shadish, W., T. Cook, and D. Campbell (2002). Experimental and quasi-experimental designs for generalized causal inference. Boston, MA: Houghton Mifflin Company.

Stylianides, G., A. Stylianides, and K. Weber (2017). Research on the teaching and learning of proof: Taking stock and moving forward. Reston, VA: National Council of Teachers of Mathematics.

Stylianou, D., M. Blanton, and O. Rotou (2015). Undergraduate students' under- standing of proof: Relationships between proof conceptions, beliefs, and classroom experiences with learning proof. International journal of research in undergraduate mathematics education 1(1), 91-134.

Warfield, J., T. Wood, and J. Lehman (2005). Autonomy, beliefs and the learning of elementary mathematics teachers. Teaching and teacher education 21(4), 439-456.

Weber, K. (2002). Beyond proving and explaining: Proofs that justify the use of definitions and axiomatic structures and proofs that illustrate technique. For the learning of mathematics 22(3), 14-17.

Weber, K. (2010). Mathematics majors' perceptions of conviction, validity, and proof. Mathematical thinking and learning 12(4), 306-336.

Weber, K. (2012). Mathematicians' perspectives on their pedagogical practice with respect to proof. International Journal of mathematics education in science and technology 43, 463482.

Weber, K., M. Inglis, and J. Mejia-Ramos (2014). How mathematicians obtain conviction: Implications for mathematics instruction and research on epistemic cognition. Educational psychologist 49(1), 36-58.

Yackel, E. and P. Cobb (1996). Sociomathematical norms, argumentation, and autonomy in mathematics. Journal for research in mathematics education 27(4), 458-477.

\section{Appendix A. Sample Proof Set}




\section{Proof Set 8}

- Let $x, y \in \mathbb{Z}$. Prove that if $3 \nmid x$ and $3 \nmid y$, then $3 \mid\left(x^{2}-y^{2}\right)$.

- Let $a, b \in \mathbb{Z}$. Show that if $a \equiv 5(\bmod 6)$ and $b \equiv 3(\bmod 4)$, then $(4 a+6 b) \equiv$ $6(\bmod 8)$.

- Prove that $2 \mid\left(n^{4}-3\right)$ if and only if $4 \mid\left(n^{2}+3\right)$.

- Let $n, m \in \mathbb{Z}$. Prove that if $n \equiv 1(\bmod 2)$ and $m \equiv 3(\bmod 4)$, then $\left(n^{2}+m\right) \equiv$ $0(\bmod 4)$.

- If $m \in \mathbb{Z}^{+}$and if $a \equiv b(\bmod n)$, then $a^{m} \equiv b^{m}(\bmod n)$.

- If $a \equiv b(\bmod n)$ and $c \equiv d(\bmod n)$, then $a c \equiv b d(\bmod n)$.

- If $a \equiv b(\bmod n)$, then $a \equiv(b+k n)(\bmod n)$.

- If $a \equiv b(\bmod n)$ and $c \equiv d(\bmod n)$, then $a+c \equiv b+d(\bmod n)$. 